\title{
Putting mental health services and suicide prevention reform into practice
}

\section{Ian Hickiea,b,c}

a Brain and Mind Centre, University of Sydney, NSW, Australia

b Guest Editor, Issue 2, 2017

c Corresponding author: ian.hickie@sydney.edu.au

\section{Article history}

Publication date: April 2017

Citation: Hickie I. Putting mental health services and suicide prevention reform into practice. Public Health Res Pract. 2017;27(2):e2721710. doi: http://dx.doi. org/10.17061/phrp2721710
Across Australia, we have just started our most radical attempt to reshape mental health services, suicide prevention and home-based psychosocial support in the past 30 years. Not since the deinstitutionalisation era of the late 1980s have our governments actively set out to change the fundamental way in which we organise and implement these key aspects of health and social care.

Two major forces are now at work. One is a direct result of the current Turnbull government's decision to implement the key organisational recommendations of the 2014 national review of mental health programs and services by the National Mental Health Commission (NMHC) ${ }^{1,2}$ The other is the nationwide implementation of the National Disability Insurance Scheme (NDIS), which has accepted the principle that a proportion of people who live with mental illness also require direct psychosocial support to participate in society. The NDIS also recognises the fundamental limitations of the economic subsidy approaches that have dominated previous efforts, highlighted in this issue by McAllister and colleagues.

The NMHC's 2014 review was commissioned by the then-incoming Abbott government. It specified a focus on Australian Government-funded programs and stated that any recommendations should assume that there would be no increase in total funding for mental health programs. In late 2015, despite serious attempts in some quarters to derail the process, Prime Minister Malcolm Turnbull launched his government's response. Importantly, he emphasised his personal commitment to growing the 'mental wealth'3 of Australia - recognising the social, economic and personal impacts of this major area of public policy.

Additionally, when the Prime Minister was challenged about the need for further financial support for reform, he restated his support for focusing on delivering better outcomes, rather than simply increasing inputs into our currently dysfunctional system. Although this view remains unpopular among mental health service providers, it represents a substantive challenge that requires a serious sector-wide response. In the 2016 election campaign, the Prime Minister committed more than $\$ 190$ million in funding to regionally based suicide prevention, expansion of early intervention services, development of new technology-enhanced solutions and strengthening of the role of the $\mathrm{NMHC}$ to improve accountability. This was in addition to the more than \$350 million each year for mental health and suicide prevention programs that comes under the new flexible funding arrangements. 
As recently highlighted by Nutbeam and Milat ${ }^{4}$, the process of public policy development and, more specifically, the move from theory to action involve a complex interplay between what is scientifically plausible, politically acceptable and practical to implement. The recommendations of the $\mathrm{NMHC}$ were developed after considering all three of these factors. The $\mathrm{NMHC}$ review has become the template for action led by the Australian Government, emphasising the key concepts of personalised care options, regionalisation of mental health services and suicide prevention, adoption of new technologies and systematic evaluation to drive future investments. $^{2}$

The $\mathrm{NMHC}$ review made bold and specific recommendations, including shifting the expenditure curve from acute, hospital-based and late-intervention health and disability services to initiatives focused on prevention, early intervention and recovery.

Sadly, the most controversial element - "Reallocate a minimum of $\$ 1$ billion in Commonwealth acute hospital funding in the forward estimates over the 5 years from 2017-18 into more community-based psychosocial, primary and community health services" (recommendation 7) - was rejected immediately by former health minister Sussan Ley just before a national health ministers' meeting with key state and territorybased colleagues. Despite this political setback, the need to invest more in noninstitutional settings remains high on the national reform agenda.

In contrast, the fundamental shift to a personcentred and regionally organised program for mental health services and suicide prevention is now being implemented. From the perspective of people who use these systems, the contribution of Crowe in this issue is particularly important. The most obvious manifestation of the move to regional delivery systems since 2016 has been the Primary Health Network (PHN)-led commissioning of those services. These programs were previously negotiated directly by the Australian Government Department of Health or its nationally funded partners, such as headspace.

The rapid movement to PHN-led commissioning of primary and specialist mental health services is a very large and complex experiment. It has created great anxiety in the mental health sector, particularly among smaller or very narrowly focused community-based organisations that fear losing direct service funding. It has also been critiqued by those who suggest that PHNs will remain far too focused on supporting local structures based on general practitioners, downgrading mental health expertise and specialisation to fit simplistic primary care and fee-for-service models, and rejecting evidence informed service models in favour of 'local solutions'. Such poorly constructed 'solutions' run the risk of favouring existing local providers with little capacity to participate in more complex multi-agency and multidisciplinary service programs.
Importantly, although multidisciplinary and active collaborative care models have long been recognised as the best way to deliver higher-quality mental health care $^{5}$, they have been strongly resisted in Australia by professional organisations that prioritise fee-for-service, solo-practitioner or single-professional group styles of practice. In this issue, the need to move to more sophisticated organisational and clinical responses is highlighted for the very important stepped-care services

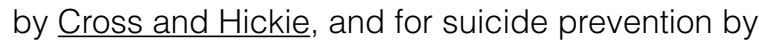
Fitzpatrick and Hooker and Page and colleagues. We are at the start of a complex and longer-term journey to build systems that will also be relevant not only to mental health, but to other areas of complex and chronic healthcare.

Three other major concerns surround this reform agenda. One is the reliance on PHNs, which do not yet have the clear organisational capacity to support such a large and complex task. The second is the concurrent, but not coordinated, introduction of the NDIS. This is particularly problematic because some states (notably Victoria) have moved money away from clinical services delivery to nonclinical psychosocial support. The net result of such shifts in financing is a direct loss of services for many people with high clinical needs.

The third concern is our lack of national investment in measuring (quantitatively and qualitatively) the impact of mental health programs on genuine health, social and economic outcomes. As highlighted elsewhere ${ }^{6}$, this has been a major failing of mental health policy implementation over the past two decades in Australia. Urgently, we need to adopt and support a more systematic outcomes-based framework ${ }^{7}$ - a concept strongly supported by the NMHC. ${ }^{1}$ Without such focus and designated investment, we run the great risk that, once again, we will invest our money and hopes in theoretical structures that do not deliver real-world improvements in access to high-quality care or effective suicide prevention.

I hope readers enjoy these themed papers and all the articles in this issue. Public Health Research \& Practice aims to deliver engaging, high-quality, peer-reviewed articles from Australian and international thought leaders, policy makers, practitioners and researchers that will inspire, provoke debate and be useful in your work.

\section{Competing interests}

$\mathrm{IH}$ has been a Commissioner in Australia's National Mental Health Commission since 2012. He is the CoDirector, Health and Policy at the Brain and Mind Centre, University of Sydney. He has previously led communitybased and pharmaceutical industry-supported (Wyeth, Eli Lily, Servier, Pfizer, AstraZeneca) projects. He is a member of the Medical Advisory Panel for Medibank Private, a Board Member of Psychosis Australia Trust and a member of Veterans Mental Health Clinical Reference Group. 


\section{References}

1. National Mental Health Commission. Contributing lives, thriving communities: report of the national review of mental health programmes and services. Canberra: NMHC; 2014 [cited 2017 Apr 12]. Available from: www. mentalhealthcommission.gov.au/our-reports/contributinglives,-thriving-communities-review-of-mental-healthprogrammes-and-services.aspx

2. Hickie IB. Time to implement national mental health reform. Med J Aust. 2015;202(10):515-7.

3. Beddington J, Cooper CL, Field J, Goswami U, Huppert FA, Jenkins $R$, et al. The mental wealth of nations. Nature. 2008;455(7216):1057-60.
4. Nutbeam D, Milat AJ. Knowledge translation: evidence into action. Public Health Res Pract. 2017;27(1):e271170.

5. Institute of Medicine (US) Committee on Crossing the Quality Chasm: Adaptation to Mental Health and Addictive Disorders. Improving the quality of health care for mental and substance-use conditions: quality chasm series. Washington, DC: National Academies Press (US); 2006.

6. Rosenberg SP, Salvador- Carulla L. Accountability for mental health: the Australian experience. J Ment Health Policy Econ. 2017;20(1):37-54.

7. Rosenberg SP, Hickie IB, McGorry PD, SalvadorCarulla L, Burns J, Christensen $\mathrm{H}$, et al. Using accountability for mental health to drive reform. Med J Aust. 2015;203(8):328-30.

\section{Copyright: (c)(ㅇ)(2)}

(C) 2017 Hickie. This article is licensed under the Creative Commons Attribution-NonCommercial-ShareAlike 4.0 International Licence, which allows others to redistribute, adapt and share this work non-commercially provided they attribute the work and any adapted version of it is distributed under the same Creative Commons licence terms. See: www.creativecommons.org/licenses/by-nc-sa/4.0/ 